\title{
Relation of Cortical Cell Orientation Selectivity to Alignment of Receptive Fields of the Geniculocortical Afferents that Arborize within a Single Orientation Column in Ferret Visual Cortex
}

\author{
Barbara Chapman, Kathleen R. Zahs, and Michael P. Stryker \\ Department of Physiology, University of California, San Francisco, California 94143-0444
}

Neurons in the primary visual cortex of higher mammals are arranged in columns, and the neurons in each column respond best to light-dark borders of particular orientations. The basis of cortical cell orientation selectivity is not known. One possible mechanism would be for cortical cells to receive input from several lateral geniculate nucleus (LGN) neurons with receptive fields that are aligned in the visual field (Hubel and Wiesel, 1962). We have investigated the relationship between the arrangement of the receptive fields of geniculocortical afferents and the orientation preferences of cortical cells in the orientation columns to which the afferents provide visual input.

Radial microelectrode penetrations were made into primary visual cortex of anesthetized adult sable ferrets. Cortical cells were recorded throughout the depth of the cortex, and their orientation preferences were determined. Cortical cell responses were then eliminated by superfusion of the cortex with either kainic acid (Zahs and Stryker, 1988) or muscimol. After the drug treatment, responses from many single units with distinct receptive fields were recorded. These responses were presumed to be those of geniculocortical afferents, because they had the response properties characteristic of LGN neurons, and because they could be recorded only in cortical layers that receive geniculate input. In 16 of 18 cases, the afferent receptive fields recorded in a single penetration covered an elongated region of visual space. In these penetrations, the best-fit line through the centers of the afferent receptive fields generally paralleled the preferred orientation of cortical cells recorded at the same site in cortex.

These results are consistent with the Hubel and Wiesel (1962) model for the construction of oriented visual cortical receptive fields from geniculate inputs with aligned receptive fields.

Each cell in the primary visual cortex of higher mammals responds best to light-dark borders at a particular orientation. This orientation selectivity must be produced at the level of the cortex because the principal visual input to these cortical cells is from the LGN, where neurons have round receptive fields

\footnotetext{
Received Aug. 14, 1990; revised Dec. 13, 1990; accepted Dec. 14, 1990.

This work was supported by a University of California at San Francisco graduate opportunity fellowship and by grants from the National Eye Institute and the Human Frontiers Science Program. We wish to thank Dr. David Ferster for a critical reading of the manuscript.

Correspondence should be addressed to Barbara Chapman at the above address.

Copyright (C) 1991 Society for Neuroscience 0270-6474/91/111347-12\$03.00/0
}

and do not exhibit marked orientation preferences. When they first described cortical orientation specificity, Hubel and Wiesel (1962) proposed a model to explain how cortical cells with simple-type receptive fields, which predominate in the layers of carnivore cortex that receive direct geniculate input, could acquire orientation selectivity from their non-orientation-selective inputs. According to this model, a given cell in the visual cortex would receive excitatory inputs from geniculate cells, the receptive fields of which are aligned in the visual field. A stimulus falling along a line of the correct orientation to excite all of these geniculate cells simultaneously would produce the best response in the cortical neuron. Stimuli at other orientations would excite only a few of the aligned geniculate cells at a time and would produce little or no response in the cortical neuron. Over the past 28 years, it has proved difficult to provide strong evidence for or against this model.

The orientation-selective cells in primary visual cortex are arranged in columns. Within one column all cells have the same orientation; cells in neighboring columns have similar preferred orientations such that the orientation changes across the surface of the cortex are gradual and progressive (Hubel and Wiesel, 1962). This orderly cortical representation of orientation allows an alternative model for cortical cell orientation preferences. Orientation might not depend on the arrangement of excitatory inputs to cortical cells from LGN afferents. Instead, the crossorientation inhibition model relies on intracortical inhibitory connections between neurons with orthogonal orientation preference to account for cortical cell orientation specificity (Blakemore and Tobin, 1972; Creutzfeldt et al., 1974). Experimental tests of the cross-orientation inhibition model have provided mixed results. In support of the model, treatment of visual cortex with pharmacological agents designed to remove intracortical inhibition tends to decrease orientation selectivity in the majority of cells (Tsumoto et al., 1979; Sillito et al., 1980). However, the cross-orientation inhibition model suggests that intracellular recordings from oriented cortical cells would reveal that inhibitory postsynaptic potentials were preferentially oriented orthogonal to the preferred orientation of the cell. Such cross-oriented IPSPs were not found (Ferster, 1986).

In order to study neuronal connections underlying orientation selectivity in visual cortex, we have attempted to look at the geniculocortical input to single orientation columns in ferret primary visual cortex. The arrangement of cortical orientation columns in the ferret (studied physiologically by D. M. Waitzmann and M. P. Stryker, unpublished observations, and with deoxyglucose by Redies et al., 1990) is similar to that seen in the more familiar carnivore, the cat (studied physiologically by Hubel and Wiesel, 1963a, and with deoxyglucose by Singer, 
1981; Schoppmann and Stryker, 1981). We have recorded from cortical cells and from a collection of geniculocortical afferents that terminate at the same location in cortex. In earlier experiments (Zahs and Stryker, 1988), geniculocortical afferents recorded in radial electrode penetrations through ferret primary visual cortex were commonly found to be dispersed over elongated regions of the visual field. We now relate the axis of this elongation to the orientation preference of cortical cells recorded along the same electrode penetration.

\section{Materials and Methods}

Animals. Fourteen adult sable ferrets were used in these studies. Ferrets were obtained from Marshall Farms (New Rose, NY) and were housed in the University of California at San Francisco animal care facility under a light cycle of 14-17 hr of light, 7-10 hr of dark.

Surgery. Ferrets were initially anesthetized with an intramuscular injection of a mixture of acepromazine $(0.04 \mathrm{mg} / \mathrm{kg})$ and ketamine $(40$ $\mathrm{mg} / \mathrm{kg}$ ) and were given atropine sulfate $(0.8 \mathrm{mg})$ every $12 \mathrm{hr}$ to preven mucus accumulation in the trachea. Following femoral vein and tracheal cannulation, anesthesia was maintained at surgical levels with intravenous thiopental sodium $(35 \mathrm{mg} / \mathrm{kg})$. Lidocaine was applied to all wound margins. Each ferret was then positioned in a modified cat stereotactic apparatus. A midline incision was made through the scalp, and the muscles overlying the skull were retracted. In most animals, 0.2$0.5 \mathrm{ml}$ cerebrospinal fluid was withdrawn through cisternal puncture using a 22-ga needle. A craniotomy was performed extending from approximately Horsely-Clarke anterior-posterior -3.0 to the caudal pole of the cortex, and from approximately Horsely-Clarke lateralmedial 1.5 to 8.5. The exposed dura was kept moist with gauze soaked in $0.9 \%$ saline. Neuromuscular blockade was produced using gallamine triethiodide $(1 \mathrm{ml} / \mathrm{kg} / \mathrm{hr}, 10 \mathrm{mg} / \mathrm{ml}$ in $5 \%$ dextrose Ringer's). Thereafter, the animal was artificially ventilated with a 3:1 mixture of nitrous oxide and oxygen. For the first $30 \mathrm{~min}$, the animal was hyperventilated to prevent cortical edema, following which the dura was retracted to expose cortical area 17

The respiratory rate and volume were set to maintain peak expired carbon dioxide between $3.8 \%$ and $4.2 \%$. Peak inspiratory pressure was always kept below $1.5 \mathrm{kPa}$. A skull screw was placed over the hemisphere contralateral to the craniotomy, and the electroencephalogram (EEG) was monitored throughout the experiment. Intravenous thiopental sodium (approximately $2 \mathrm{mg} / \mathrm{kg} / \mathrm{hr}$ ) was administered whenever there was any sign of EEG desynchronization. The animal's heart rate was also monitored throughout the experiment, and its temperature was maintained at $37.5^{\circ} \mathrm{C}$ using a feedback system. Prior to fitting the animal's eyes with contact lenses of appropriate refractive power, pupils were dilated with $2 \%$ atropine sulfate, and nictitating membranes were retracted with $10 \%$ phenylephrine hydrochloride.

Kainate treatment. In 2 ferrets, the cortical surface was photographed using a Nikon 35-mm camera mounted on a Zeiss operating microscope. Photos were printed at a final magnification of approximately $28 \times$ allowing for accurate notation of the positions of microelectrode penetrations with respect to cortical vasculature. Cortical cell responses in several radial penetrations were then recorded (see below). Following recording of cortical units, a piece of filter paper (Whatman 4, approximately $2 \times 7 \mathrm{~mm}$ ) was soaked in kainic acid (Sigma, k0205; $10 \mathrm{~mm}$ in $0.9 \%$ salirie) and placed over the caudal portion of the exposed cortex Kainic acid was superfused onto this filter paper at a rate of $60 \mu \mathrm{l} / \mathrm{hr}$ for 12-14 hr through Silastic tubing (Dow Corning) attached to a syringe held in an infusion pump. The anterior portion of exposed cortex was covered with a separate piece of filter paper soaked in $0.9 \%$ saline Saline-moistened cotton was placed around the exposure and covered with Saran wrap (Dow Chemical) to create a moist chamber over the exposed cortex.

Muscimol treatment. In 11 ferrets, a piece of Gelfoam (approximately $0.2 \mathrm{~mm}$ thick, $2 \times 7 \mathrm{~mm}$ ) was placed over the caudal portion of the exposed cortex. A recording electrode (see below) was then positioned perpendicular to the brain surface with its tip just touching the cortical surface through a hole in the Gelfoam. A piece of Silastic tubing containing muscimol (Sigma, M1 523; $50 \mathrm{~mm}$ in $0.9 \%$ sterile saline) attached to a syringe held in an infusion pump had its terminal $2 \mathrm{~cm}$ filled with $0.9 \%$ saline and its end placed on the Gelfoam less than $1 \mathrm{~mm}$ away from the recording electrode. Following the recording of cortical units in one radial penetration (see below), the microelectrode was withdrawn to approximately $200 \mu \mathrm{m}$ above the presumed location of layer IV. Muscimol was then infused through the Silastic tubing at a rate of 74 $\mu \mathrm{l} / \mathrm{hr}$ for approximately $2 \mathrm{hr}$

Electrophysiological recording. Lacquer-coated tungsten microelectrodes (Hubel, 1957) were used to record extracellularly. Impedances ranged between 1.0 and $2.0 \mathrm{M} \Omega$, and electrode tips tapered from a diameter of $10-15 \mu \mathrm{m}$ to a very sharp point over approximately $30 \mu \mathrm{m}$. Electrodes were connected to a preamplifier (Grass P15). The signal was capacity compensated and band-pass filtered at $0.1-10 \mathrm{kHz}$, then displayed on an oscilloscope (Tektronix 5115) and played on an audio monitor (Grass AM8). Radial electrode penetrations were made into area 17. Cortical cell receptive fields were studied at $200-\mu \mathrm{m}$ intervals Receptive fields were first hand plotted using moving bars of light produced by a Zeiss hand lamp to determine location, ocular dominance, and preferred orientation. Then an orientation-tuning histogram was compiled, using a computer to drive an optical display that swept ligh hars across the receptive fields at 36 different orientations, randomly interleaved, and to record unit responses to each stimulus presentation.

In kainate-treated ferrets, several radial electrode penetrations were performed, and their locations were marked on the photograph of the brain surface. Cortical units were recorded, and their receptive fields were plotted throughout the depth of the cortex. The microelectrode was then withdrawn from the brain. After kainate infusion, microelectrode penetrations were made as close as possible to the penetrations where cortical units had been recorded.

In order to determine whether it was possible to return to the same orientation column following the 12-hr time lapse necessary for the kainate infusion, two microelectrode penetrations were made into the non-kainate-treated hemisphere of one animal, and receptive field locations and orientation preferences were recorded. Twelve hours later, penetrations were made at these same locations, and cortical cell receptive field properties were again assessed. Receptive field centers in the later penetrations were all within $3^{\circ}$ of those recorded earlier in the same penetration, and preferred orientations never varied by more than $10^{\circ}$ from those recorded earlier.

In muscimol-treated ferrets, data relating afferent receptive fields to cortical cell orientation resulted from only one penetration per animal. After recording from cortical cells throughout the depth of the cortex, the microelectrode was withdrawn to $200 \mu \mathrm{m}$ above the presumed location of the top of layer IV, based on the locations at which afferentlike "swish" could be recorded. After muscimol infusion the microelectrode remained in the same penetration in which cortical responses had been recorded.

Data were discarded from any penetration in which the preferred orientation of cortical units at the top of layer II differed by more than $10^{\circ}$ from the preferred orientation of units in layer IV.

Kainate or muscimol infusion was stopped when little or no activity could be recorded in supragranular layers. The microclectrode was advanced in $40-\mu \mathrm{m}$ steps until vigorous visually driven activity from presumed geniculocortical afferents was encountered. The electrode was then advanced in $20-\mu \mathrm{m}$ steps, and the receptive fields of units at each site were studied using flashing or rapidly moving spots of light produced by a Zeiss hand lamp or, in one animal, by the computer-driven optic bench. For each afferent, receptive field, location, size, center type, and the eye through which a response could be elicited were noted. Units were assessed for orientation preference using moving bars of light. The recordings were terminated after the electrode had been advanced 200 $\mu \mathrm{m}$ below the last recorded afferent. In 10 cases, the electrode was then slowly withdrawn up through layer IV, and the afferent receptive fields were plotted again. Electrolytic marking lesions were made in each penetration, usually at both ends of the region within which presumed afferent units had been recorded.

In 11 animals, receptive fields were plotted using a "blind" procedure; that is, the person plotting the afferent receptive fields did not know the location or orientation preference of the cortical cell receptive fields previously recorded at the same site.

Lateral geniculate nucleus stimulation. In one ferret, two concentric bipolar electrodes (Rhodes SNE100) were placed in the LGN. The electrodes were aligned rostrocaudally, $2 \mathrm{~mm}$ apart, with the caudal electrode in a region of LGN where recorded units had centrally located receptive fields. A tungsten recording electrode (see above) was placed in area 17. Cortical unit responses to light and to LGN stimulation (50 $\mu \mathrm{A}$ to $1.5 \mathrm{~mA}, 100-200 \mu \mathrm{sec}$ duration, $100-500 \mathrm{~Hz}$ ) were recorded. Muscimol was then infused onto the cortex as described above. After 


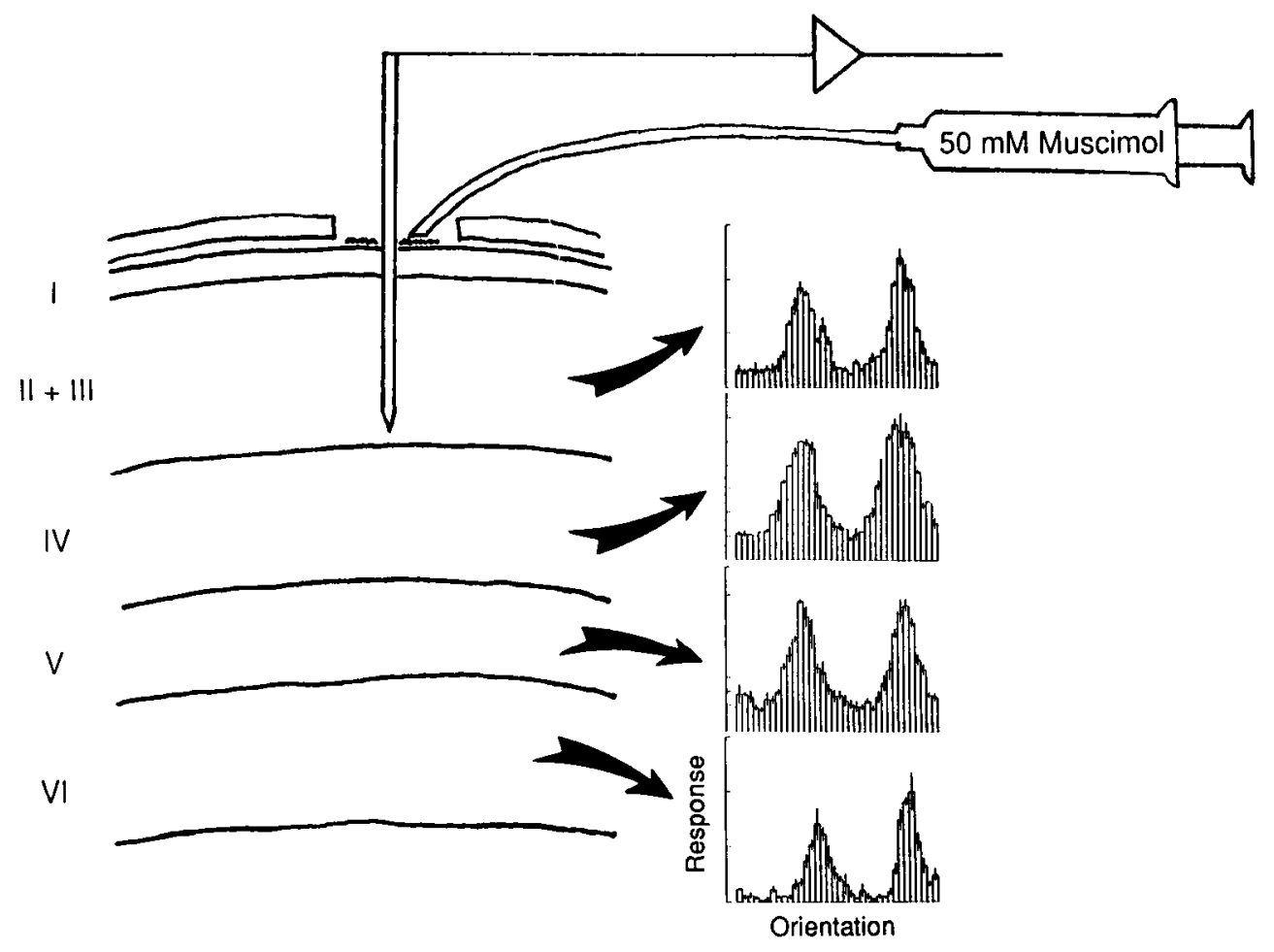

Figure 1. Experimental setup and cortical cell orientation-tuning histograms. A radial microelectrode penetration through the depth of cortical area 17 is illustrated. Orientation-tuning histograms for four single-unit recordings from cells located at the arrows are shown on the right. Fach histogram shows the mean response in spikes/sec to three presentations of 36 randomly interleaved orientations of moving light bars swept across the cell's receptive field: 0 represents a vertical bar moving leftward, and 90 represents a horizontal bar moving downward. Following these recordings, the electrode was withdrawn to approximately the depth shown, just above layer IV. Muscimol $(50 \mathrm{~mm})$ was then superfused onto Gelfoam surrounding the electrode to silence cortical cell activity prior to recording the responses of geniculocortical afferents. cortical units were silenced, the responses of presumed geniculocortical afferents to light and to LGN stimulation were recorded.

Histology. The brains of seven animals (two kainate-treated, five muscimol-treated) were processed for histological reconstruction of electrode penetrations. After the recording session, the animals were very deeply anesthetized with intravenous pentobarbital $(50-100 \mathrm{mg} / \mathrm{kg})$ and perfused intracardially with $0.9 \%$ saline followed by $10 \%$ formol saline. After postfixing in $10 \%$ formol saline, the brain was blocked, and the occipital cortex was sunk in $30 \%$ sucrose formalin and embedded in albumin-gelatin. Coronal sections were cut at $40 \mu \mathrm{m}$ on a freezing cryostat, mounted on slides, and stained with cresylecht violet to locate electrode tracks and marking lesions.

Quantitative analysis. Experiments where few afferents were recorded were not suitable for analysis because the aim of the study was to relate the arrangement of a group of afferent receptive fields to the cortical cell orientations. Data were therefore analyzed only from the 17 penetrations where 8 or more afferent units were recorded (data from 1 penetration with 6 afferent units were discarded; 3 or fewer afferents were recorded in all other penetrations that were not analyzed). Afferent receptive fields of different center type from the same penetration were analyzed separately. A total of 30 afferent receptive field arrays were analyzed: 18 from this study and an additional 12 from previous experiments (Zahs and Stryker, 1988) where afferent receptive fields were mapped but cortical cell orientation was not determined.

A quantitative analysis was performed to determine how well geniculocortical afferent receptive fields from a single electrode penetration were aligned with one another in visual space. For each array of afferent receptive fields, the principal axis of elongation of the afferent centers was calculated, along with its correlation coefficient $\left(r^{2}\right)$. The principal axis of elongation is not simply the regression line of the receptive field elevations on their azimuths, because neither coordinate is a dependent variable. Furthermore, if a standard regression line were calculated, correlation coefficients would be zero for afferent receptive fields aligned vertically or horizontally. The principal axis of afferent receptive field arrays was therefore calculated as the axis that, when rotated to $45^{\circ}$, produces the maximum correlation coefficient. This maximum correlation coefficient was the $r^{2}$ used in the analysis.

To calculate the extent to which this measured alignment was significantly different from chance, a Monte Carlo analysis was performed as follows: For each array of afferent receptive fields, 10,000 simulated arrays of receptive fields were generated on a DECstation 3100 com- puter. Each simulated array contained the same number of afferent receptive fields as were encountered in the electrode penetration, but each receptive field was assigned a random location while maintaining its distance from the center of the array. The value of $r^{2}$ was calculated as above for each of the 10,000 simulated arrays. The percentile occupied by the experimental $r^{2}$ in the distribution of randomized $r^{2} s$ was calculated and called the "alignment significance."

\section{Results}

In all penetrations analyzed in this study, visual cortical cells were orientation selective, and the preferred orientations of the cortical cells did not change significantly within the penetration, which extended from the surface of the cortex down to white matter. An example of orientation-tuning histograms for single cortical units recorded in differcnt laycrs of cortcx within onc penetration is shown in Figure 1.

After superfusion of kainate for 12-14 hr (as shown previously; Zahs and Stryker, 1988) or muscimol for 2-3 hr, neuronal activity in supragranular layers of area 17 was almost entirely eliminated. Occasionally, small amplitude units could be recorded that responded to rapidly moving stimuli but not to light flashes and that lacked orientation preference to slowly moving light bars but did not exhibit center-surround receptive field organization. In general, however, neither spontaneous nor visually driven activity could be recorded in the upper layers. Within layer IV, spontaneous activity was high, and visual responses were easily elicited. Several single units could be isolated at most recording sites based on their nonoverlapping receptive fields and on differences in their action-potential wave forms. These units were presumed to be the terminals of geniculocortical affercnts becausc they had the response properties identical to those of neurons recorded in the LGN and were recorded only after the electrode had reached cortical layer IV, and not above. The presumed afferents were monocularly driven; they 


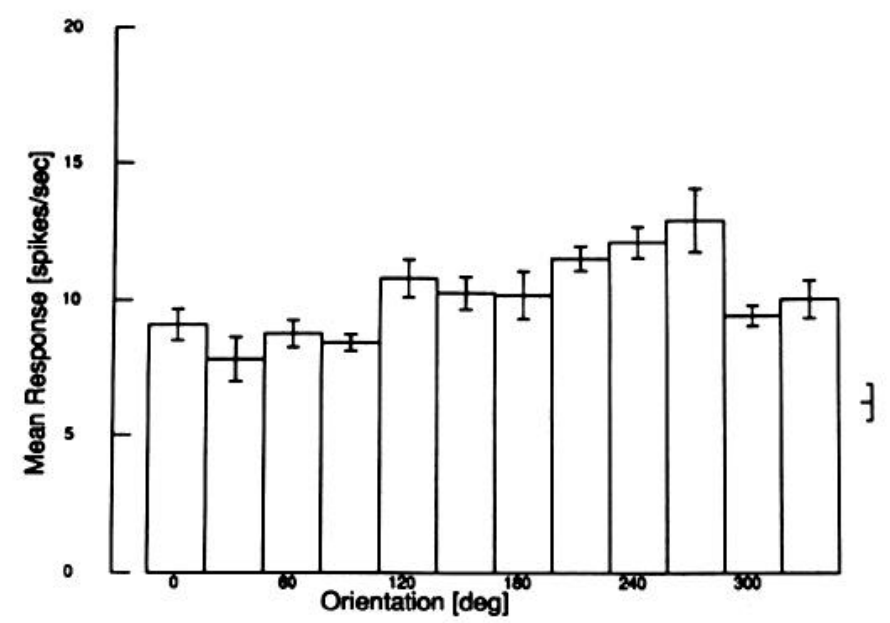

A

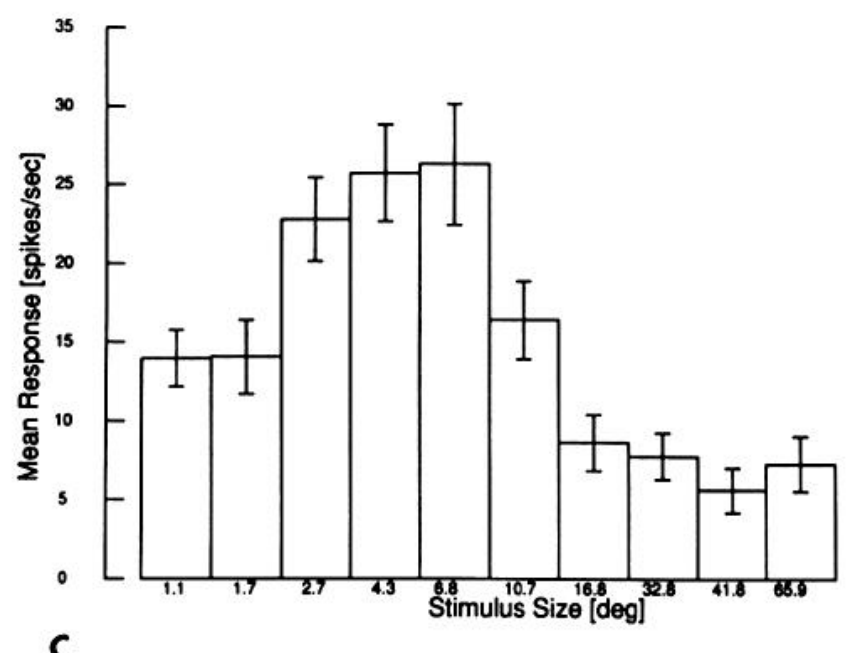

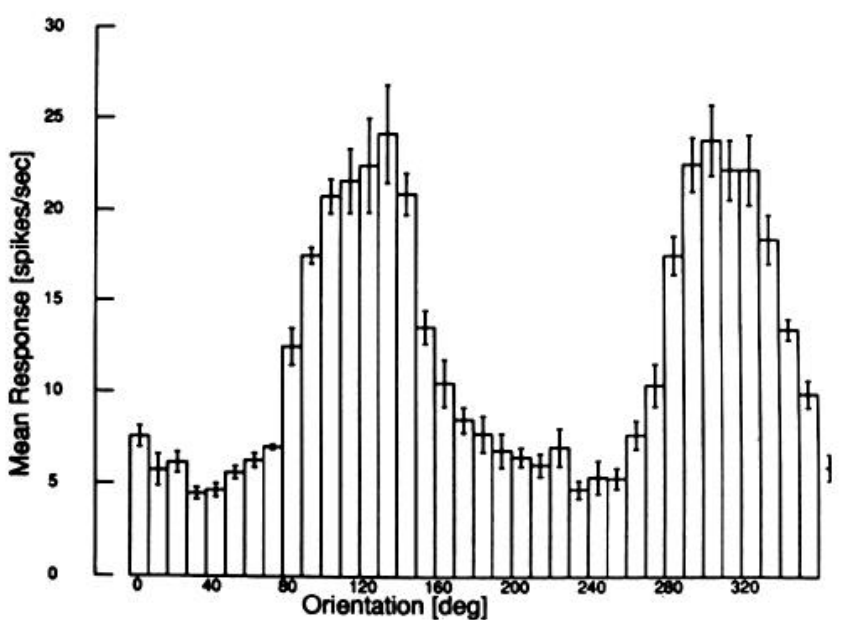

B

Electrically-Evoked Spikes

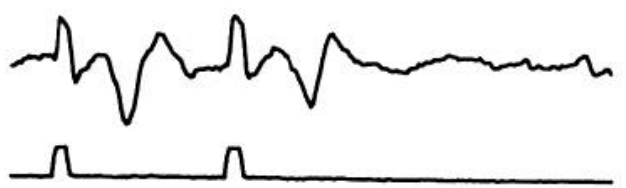

Visually-Evoked Spike

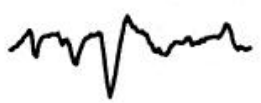

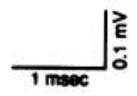

D

$\mathbf{E}$

Figure 2. Geniculocortical afferent responses and location of afferent recordings. For orientation-tuning histograms, 0 represents a vertical bar moving leftward, and 90 represents a horizontal bar moving downward. A, Orientation-tuning histogram for geniculocortical afferent. Mean response in spikes/sec is shown to three presentations of 12 randomly interleaved orientations of moving light bars swept across the afferent's receptive field. The unit shows no orientation preference. Error bars indicate SEM. B, Orientation-tuning histogram for an area 17 cortical unit. Mean response in spikes/sec is shown to three presentations of 36 randomly interleaved orientations of moving light bars swept across the cell's receptive field. The unit is orientation selective. Error bars indicate SEM. C. Stimulus size series for geniculocortical afferent. Mean response in spikes/sec to three presentations of 10 randomly interleaved sizes of light spot flashed onto the afferent's receptive field. The afferent shows center-surround receptive field organization, responding best to a stimulus large enough to fill the center of the receptive field, and poorly to larger stimuli that impinge on the inhibitory surround of the field. Error bars indicate SEM. $D$, Visually and electrically driven action potential of a geniculocortical afferent. The top trace shows the response of an afferent recorded in cortical layer IV to the 450-Hz electrical stimulation of the LGN shown just below. The lower trace, also recorded in cortical layer IV, shows the response of an afferent to visual stimulation with a flashing spot of light. The visual stimulus was on continuously during the interval shown. The unit studied here produced a particularly large electrical signal. Note that smaller spikes from other afferents are also evident in the visual response. $E$, Histological reconstruction of electrode penetration. A photomicrograph of a Nissl-stained section through area 17 is shown. The open arrows mark the upper and lower boundaries of the region from which afferent responses were recorded following muscimol superfusion. The solid arrow points to an electrolytic marking legion. Note that all afferent recordings were within layer IV. Scale bar, $200 \mu \mathrm{m}$.

responded reliably to repeated light flashes or rapidly moving stimuli within receptive fields of appropriate size; they showed no preference for stimulus orientation (Fig. $2 A$ ) in contrast to the tightly orientation-tuned responses seen in cortical cells (Fig. $2 B$ ); they exhibited center-surround antagonism (Fig. $2 C$ ); they had very fast $(<200 \mu \mathrm{sec})$ small $(20-100 \mu \mathrm{V}$, usually $<50 \mu \mathrm{V})$ action potentials (Fig. 2D); they consistently followed high-frequency electrical stimulation of the LGN (Fig. 2D); and they were located in layer IV in all seven penetrations reconstructed histologically (Fig. 2E). Afferent unit recordings stopped abrupt- ly at the bottom of layer IV, and electrical signals were almost completely absent in layer $\mathbf{V}$. When the electrode entered layer VI, geniculocortical afferent units were again encountered; the receptive fields of these layer VI afferents were not quantitatively studied.

Figure 3 shows the receptive field of a cortical cell recorded at the top of layer IV, the preferred orientation of that cell determined from its orientation-tuning histogram, and the afferent receptive fields recorded in each microelectrode penetration. Because the ferret has segregated patches of on- and off- 
center geniculate afferents in visual cortex (Zahs and Stryker, 1988), most electrode penetrations contained afferents of only one center type. However, in one penetration, more than eight afferents of each center type were recorded. This allowed 18 afferent receptive field arrays to be analyzed from the 17 penetrations performed. Figure 3 illustrates the ranges observed in the degree of elongation of afferent receptive field arrays and in the fit between the preferred orientations of the cortical cells in layer IV and the principal axes of elongation of the afferent arrays. These plots, which constitute the primary data of this experiment, are further analyzed below.

Cortical cell receptive fields and afferent receptive field arrays showed varying degrees of overlap. In some penetrations (Fig. $3 F, G, M)$, there appeared to be no overlap between the receptive fields of the cortical cell and those of the afferents. Possible explanations for this variable degree of overlap are discussed below.

Results of the Monte Carlo analysis that tests the significance of afferent receptive field alignment are shown in Figures 4 and 5. The histograms in Figure 4 show the distributions of $r^{2} s$ calculated for the 10,000 simulated afferent arrays derived from each of three electrode penetrations. The arrows point to the $r^{2} \mathrm{~s}$ obtained from the experimental data, and the insets show the experimentally obtained afferent receptive fields for each case. The Monte Carlo measure of the significance of receptive field alignment is the percentile occupied by the experimental $r^{2}$ in the distribution of randomized simulation $r^{2}$ s. For arrays of receptive fields that appear by eye clearly to be elongated (Fig. $4 A), r^{2}$ for the experimental data falls well outside the distribution of values of $r^{2}$ for the random simulated arrays, making the degree of alignment high. For clustered arrays of afferents (Fig. 4C), the experimental $r^{2}$ falls well within the distribution, showing that the degree of alignment is not significant. An intermediate case is shown in Figure $4 B$. A histogram showing the alignment significance for all of the experimental data is shown in Figure 5. Sixteen of the 18 afferent receptive field arrays are significantly aligned with $>90 \%$ confidence. This distribution of alignment significances is similar to the distribution calculated from afferent receptive field arrays obtained in a previous study (Zahs and Stryker, 1988), where cortical cell orientation was not determined; 27 out of 30 penetrations in the total data set have alignment significance greater than $90 \%$.

Two possible artifacts might have caused afferent receptive field arrays recorded in this study to appear to be aligned, but both of these artifacts can be discounted. First, the observed alignment could be a reflection of the retinotopic map on the cortex. An electrode penetration that failed to travel radially through the cortex along a line of projection could yield an elongated array of afferent receptive fields as the electrode moved across the retinotopic map. In that case, however, the receptive fields of successively encountered afferents would be expected to progress in an orderly fashion across the visual field. No such progression was present in any electrode penetration in these cxpcriments. Instcad, reccptive ficlds of successivcly cncountered afferents zigzagged back and forth through visual space as the electrode advanced. Figure 6 shows a typical example of this, with the receptive fields numbered in the order in which they were encountered, and with arrows connecting successively encountered receptive fields. The second artifact that could account for observed alignment of afferent receptive fields would be eye movements occurring during the recordings of the afferents. However, eye movements are not consistent with the data, because afferent fields at both ends of an array were often recorded simultaneously at one depth in cortex. Also, in those penetrations where receptive fields were recorded both as the electrode advanced down through layer IV and as the electrode was withdrawn, many of the same afferent receptive fields were plotted at the same depth on the way down and on the way up.

No relationship is seen between the alignment significance of afferent receptive field arrays and the degree of orientation tuning seen in the cortical cells recorded at the same site. Figure 7 shows the tuning of cortical cells, measured as the average halfwidth at half-height of the tuning histograms of all the supragranular cells recorded in each penetration, plotted against the alignment significances of the afferent receptive field arrays. The two sites where afferent receptive fields were clustered (Fig. $3 P, Q$ ), producing low alignment significances, have cortical cell orientation tunings slightly better than the mean of tuning at all the cortical sites.

The two clustered afferent receptive field arrays could represent cortical locations where the afferents are arranged differently than at the other locations studied, or they could merely result from randomly sampling a small number of afferents from a larger population that is actually elongated. In order to determine how likely it is that such clustered arrays would be recorded from a large population of afferents forming an elongated array, the following analysis was performed: A universe was constructed consisting of all of the experimentally recorded afferent arrays placed in register such that their principal axes and their geometric centers lined up. Differences in the distances between receptive fields due to differences in cortical magnification factor between penetrations could affect the outcome of the simulation. Therefore, the analysis was performed using random samples drawn from a universe in which the experimental receptive field arrays were not only in register, but also normalized for magnification factor. Random samples of receptive fields were drawn from this universe shown in Figure $8 A$. The sizes of the random samples were matched to the numbers of afferents recorded in the experimental electrode penetrations; each real penetration was represented by 10 samples of the same size in the simulation. The alignment significance of each random sample was calculated, and the distribution of alignment significances was compared to that of the experimental data. The results of this analysis are shown in Figure 9, which plots the cumulative percentage of real and simulated arrays occurring at each alignment significance. Although a few arrays with low alignment significance are seen in the simulated data, these represent a much smaller percentage of the total simulated data than the percentage represented by the two clustered arrays in the experimental data. In addition, the two experimentally observed arrays with the lowest alignment significance are more closely clustered than any of the simulated arrays, having a smaller mean distance of receptive field centers from the geometric center of the array than do any of the simulated arrays. The same result was seen to a lesser degree when neither afferent receptive field arrays nor simulated data were normalized for magnification factor (data not shown). This analysis suggests that the 2 afferent receptive field arrays with very low elongation significance are unlikely to have been evident merely because of the small sample size. Rather, they appear to represent sites in visual cortex at which geniculocortical afferent organization differs from that found in most locations.

Figure $8 B$ shows a universe of possible afferent receptive field positions constructed as in Figure $8 A$, except that only the 18 


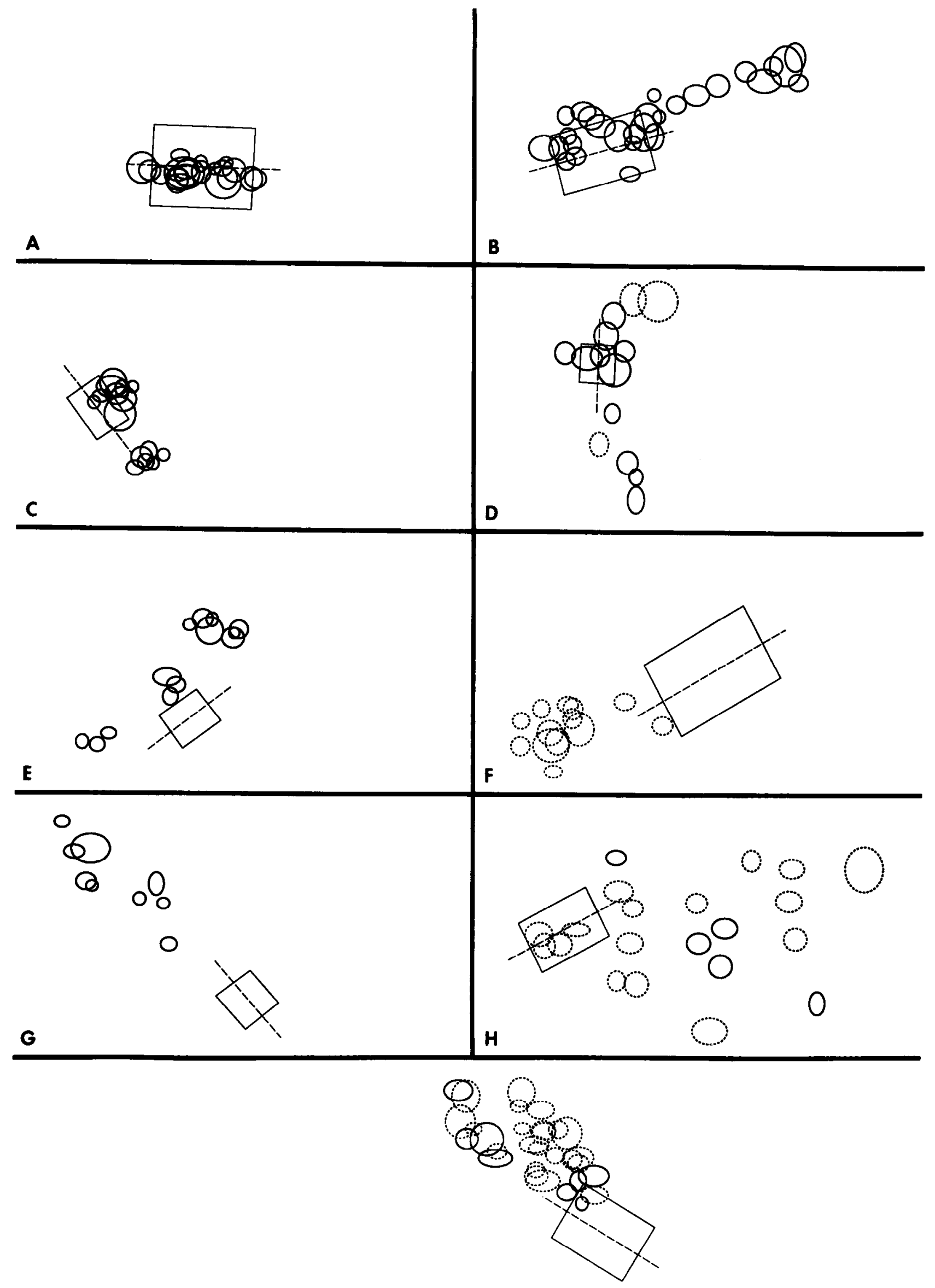



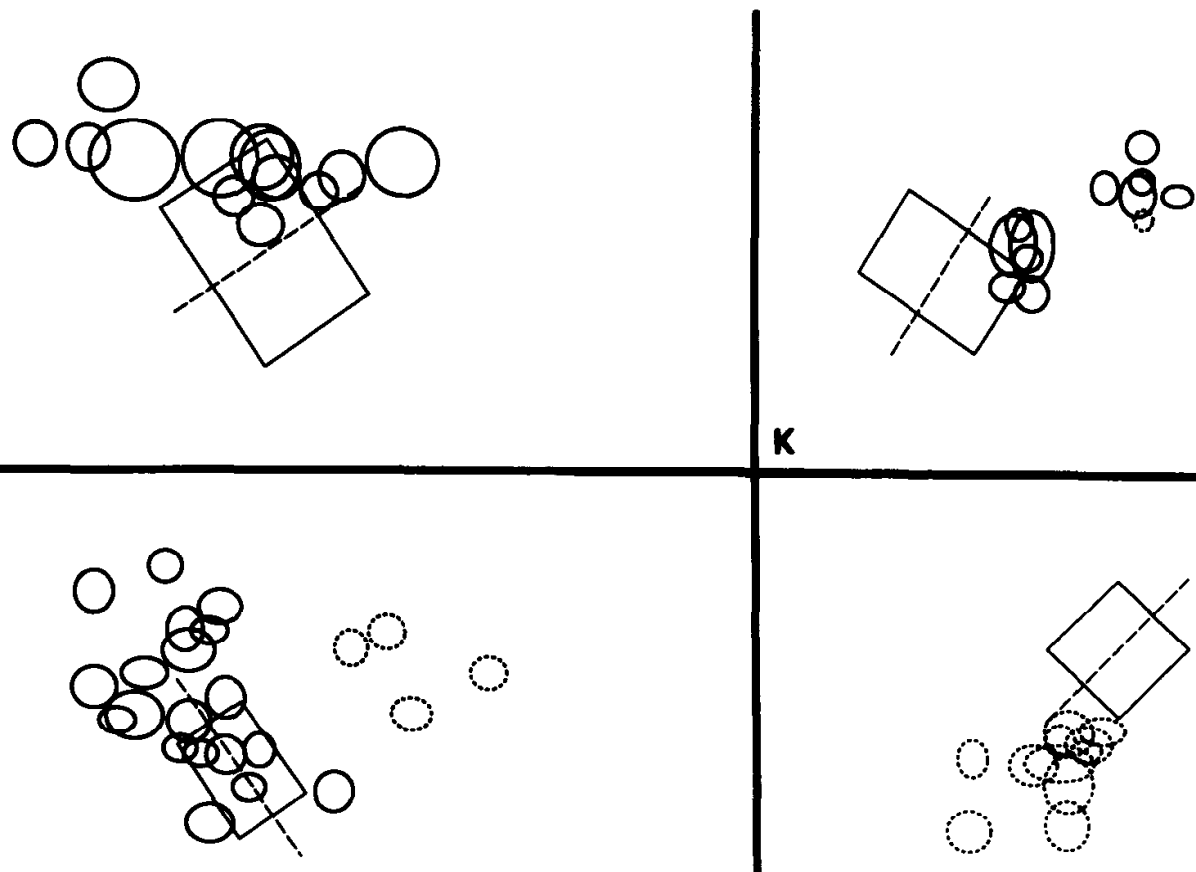

$\mathbf{L}$

M

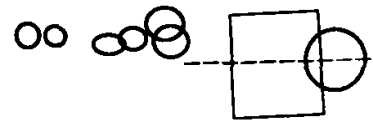

O
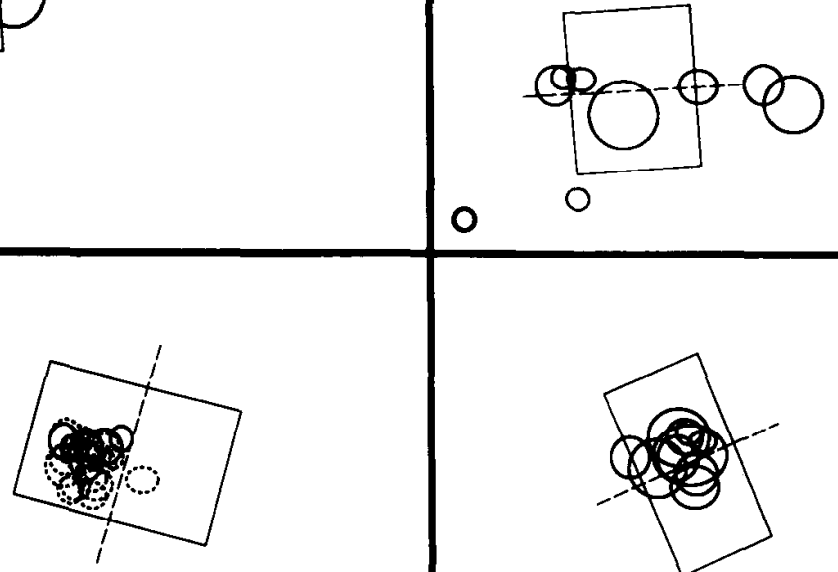

P

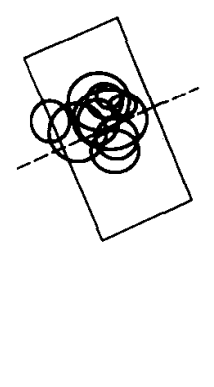

Figure 3. Receptive fields of cortical cells and afferents recorded in all 17 microelectrode penetrations. On-center afferents are shown as solid ovals, off-center afferents as broken ovals. For each penetration $(A-Q)$, the receptive field of a cortical cell recorded at the top of layer IV is shown as a rectangle, with its preferred orientation, determined from its orientation tuning histogram, shown as a broken line. Scale bar, $2^{\circ}$.

afferent arrays recorded in this study were used and the data from each penetration have been rotated to align the cortical cell preferred orientations rather than the afferent receptive field array principal axes. This universe is similar to that shown in Figure $8 A$. The universes shown in Figure 8, $A$ and $B$, represent our best estimates of the aggregate receptive field shape of the collection of geniculocortical inputs to a single orientation column.

The correspondence between cortical cell orientation and the spatial arrangement of geniculocortical afferent receptive fields at the same cortical site is illustrated in Figure 10. The principal axis of elongation of the afferent receptive field centers is plotted 

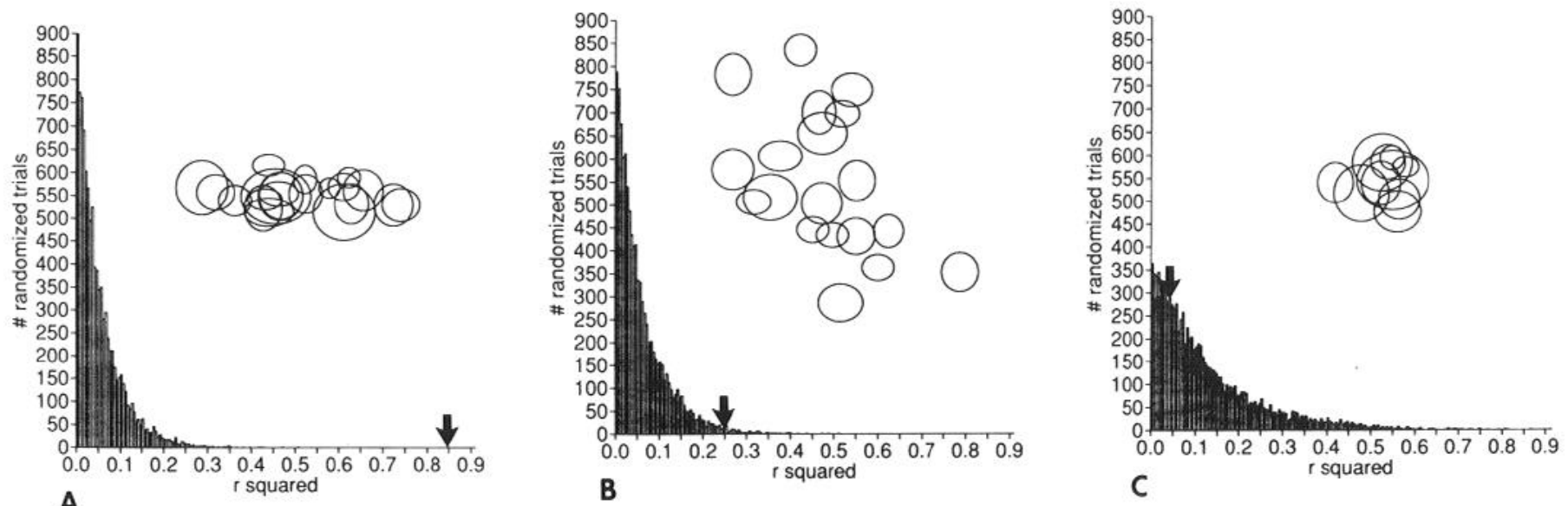

Figure 4. Monte Carlo analysis of the significance of afferent receptive field alignment. For each set of recorded afferent receptive fields, 10,000 simulated arrays of receptive fields were generated by assigning receptive fields to random locations while maintaining each field's distance from the center of the array. The value of $r^{2}$ was then calculated for each of the simulated arrays. The histograms show the distributions for $r^{2}$ obtained in three cases. The arrows point to the $r^{2}$ obtained from the experimental data in each case. Insets show the experimentally obtained afferent receptive field locations. $A$, For arrays that appear clearly elongated, $r^{2}$ for the experimental data falls well outside of the distribution of values of $r^{2}$ for the simulated random arrays. $B$, An intermediate case. $C$, For a clustered array, the experimental $r^{2}$ falls well within the distribution.

versus the preferred orientation of layer IV cortical cells as measured from orientation tuning histograms. Data from all 16 penetrations in which the alignment significance is greater than $90 \%$ are included. The diagonal line $(x=y)$ indicates the predicted result if cortical cell and afferent orientations were to match perfectly. In the majority of experiments the afferent receptive fields were plotted with no knowledge of the cortical

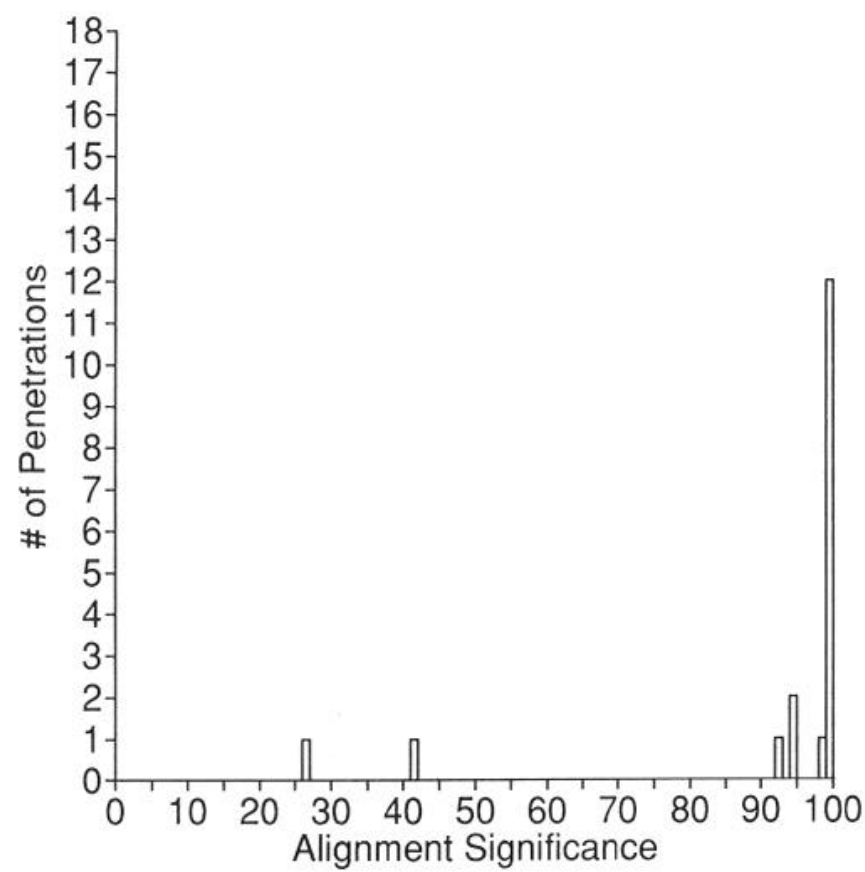

Figure 5. Alignment significance for all 18 afferent receptive field arrays. The Monte Carlo measure of the significance of receptive field alignment is the percentile occupied by the experimental $r^{2}$ in the distribution of $r^{2}$ s obtained in the simulation illustrated in Figure 4. This alignment significance is shown for the 18 afferent receptive field arrays analyzed in this study. Sixteen of 18 arrays are significantly aligned with greater than $90 \%$ confidence.

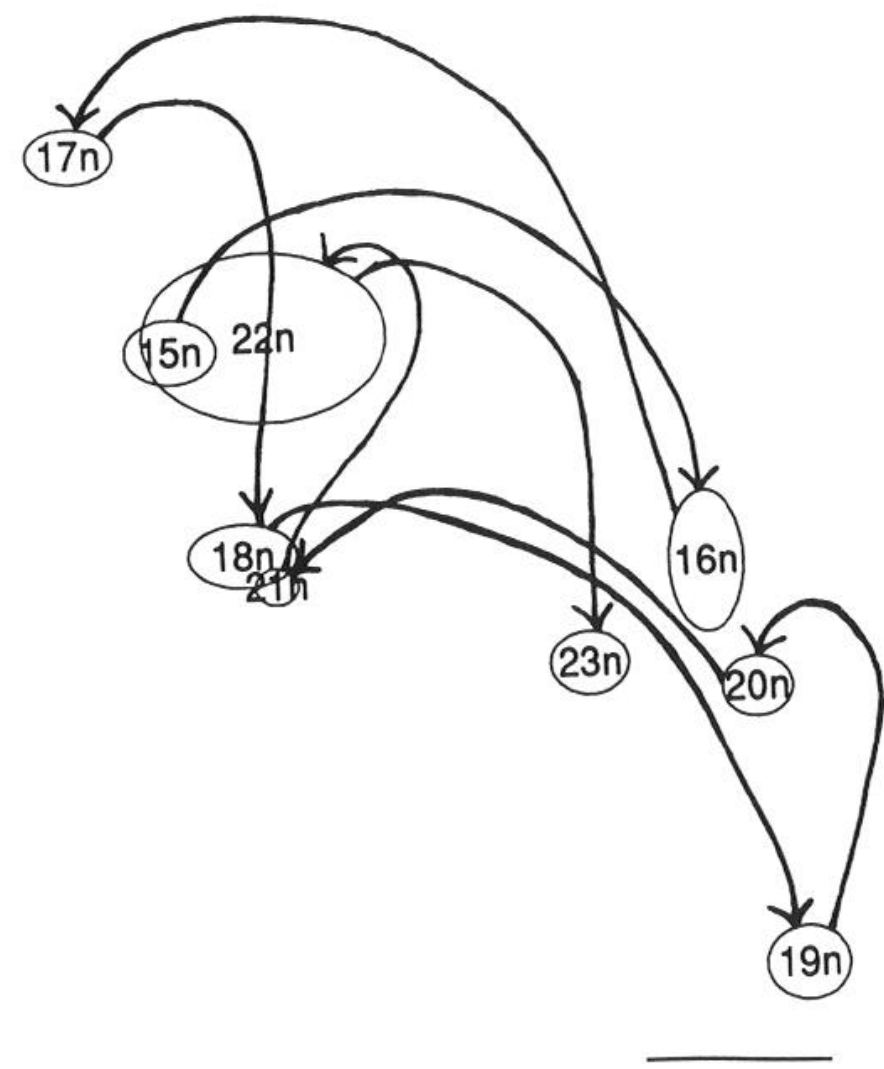

Figure 6. Receptive field positions of successively encountered afferents recorded in one microelectrode penetration. Numbers indicate the order in which the receptive fields were encountered as the electrode advanced down through layer IV; arrows connect successively encountered receptive fields. No orderly progression of receptive fields across visual space is seen, indicating that the elongated arrays of afferents found do not merely reflect microtopography of the retinotopic map on the cortex. Scale bar, $2^{\circ}$. 


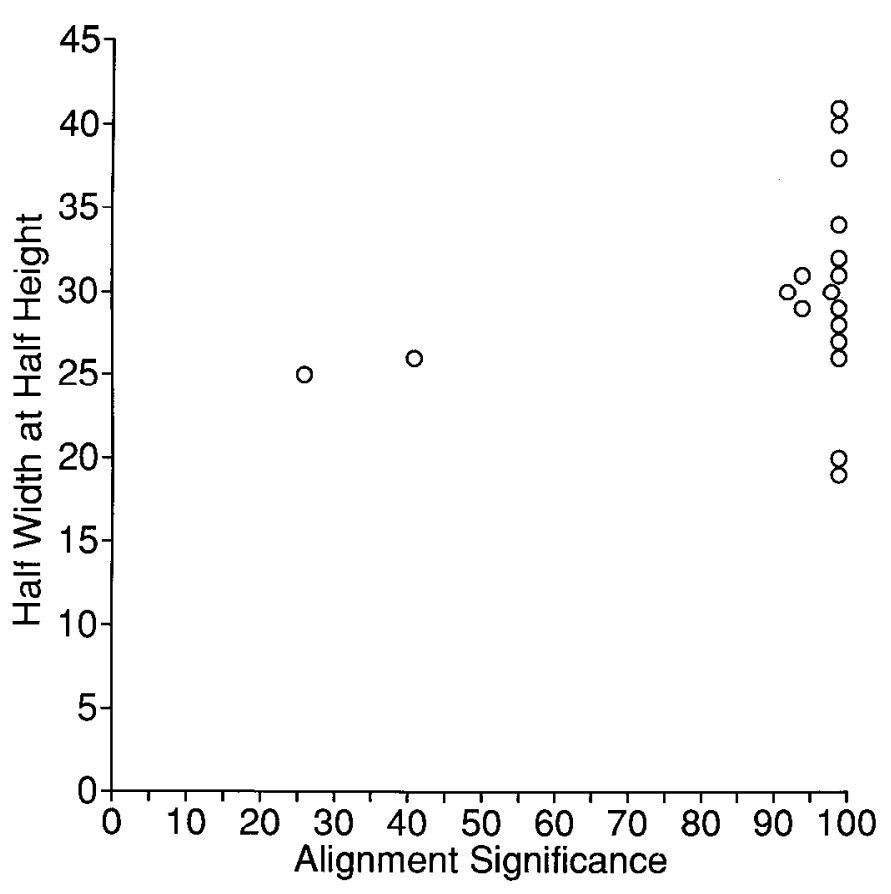

Figure 7. Relationship between alignment significance of afferent receptive fields and orientation tuning of cortical cells recorded at the same site. Alignment significance is plotted against mean half-width at half-height for supragranular cortical cells recorded in each penetration. There appears to be no relationship between the degree of alignment of afferents and the strength of cortical orientation tuning. Note that the cortical cells are nicely tuned at the two locations where afferent receptive field arrays are not elongated.

cell orientation previously recorded in the penetration. This blind procedure resulted in an equally good match between cortical cell and afferent orientations as was seen in the rest of the experiments. Although there are two sites where the mismatch between cortical cell orientation and afferent receptive field array axis is nearly $30^{\circ}$, in 12 of 16 cases the match is closer than $10^{\circ}$. Such a match is essentially perfect, because cortical cell orientation was measured in $10^{\circ}$ steps.

\section{Discussion}

Receptive fields of individual geniculocortical afferents can be recorded in ferret area 17 following pharmacological suppression of cortical cell activity. Treatment of the cortex with either the glutamate agonist kainate, which acts as an excitotoxin, or with the GABA agonist muscimol, which mimics intracortical inhibition, silences the action-potential firing of visual cortical neurons. Units recorded after such suppression of cortical activity are clearly geniculocortical afferents: They have the same receptive field properties as LGN neurons, they are recorded only in the geniculocortical input layers of cortex, and they respond quickly, without failures, and with consistent response latency to electrical stimulation of the LGN. That the two functionally distinct methods of silencing cortex result in identical recordings of LGN-like units provides further evidence that these units are in fact afferents rather than degraded responses of cortical cells. The recorded afferents appear likely to terminate in, and provide visual input to, the orientation column within which they were encountered. Although afferent fibers are known to pass through layer $\mathrm{V}$, no afferent responses could be recorded within that layer in these experiments. This suggests that genicu-
A

A 0
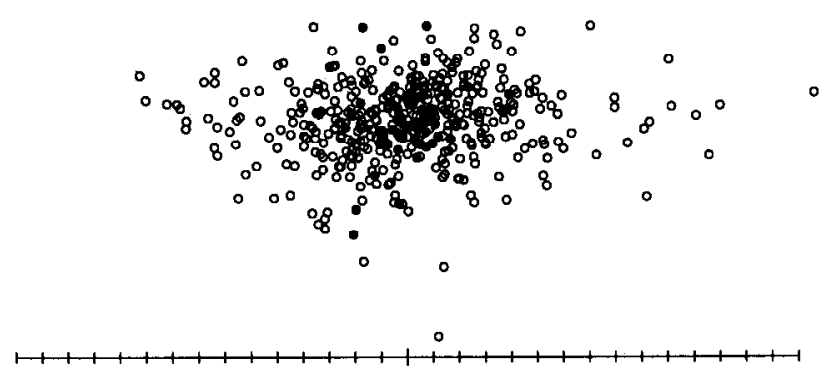

B

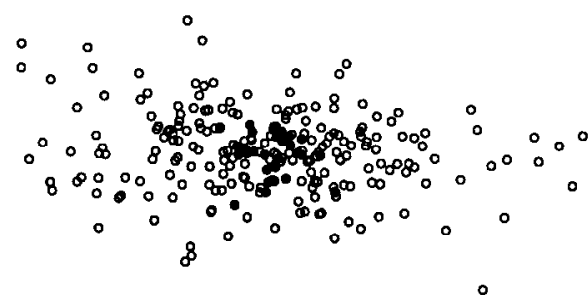

Figure 8. A, A universe of possible afferent receptive field locations was constructed from the 18 afferent receptive field arrays obtained in this study, plus 12 afferent receptive field arrays from a previous study (Zahs and Stryker, 1988). Afferent receptive field locations were normalized for magnification factor by calculating the mean radius of the receptive fields encountered in each penetration, then multiplying the distance of each receptive field center from the center of the array by the average mean radius for all penetrations divided by the mean radius for that particular penetration. All the arrays were placed in register such that their principal axes of elongation were lined up horizontally and their geometric centers were superimposed. Afferent receptive field centers (not the entire fields) are shown. Receptive field centers from penetrations where afferents were significantly aligned are shown as open circles; unaligned arrays are shown as solid circles. $B$, Universe of possible afferent receptive fields constructed as in $A$, except that only the 18 afferent arrays from this study were used and each array is rotated to align the preferred orientations of cortical cells rather than the principal axes of the afferent arrays. Tick marks represent $1^{\circ}$ of visual angle.

locortical afferent action potentials are only large enough to record at their axon terminal arbors using the electrodes employed in this study.

Geniculocortical afferent receptive fields recorded in single radial penetrations through layer IV of ferret area 17 form arrays that often appear to be elongated in visual space. A Monte Carlo analysis confirms that in 16 of 18 cases studied the afferent arrays from single penetrations were significantly aligned. The axis of this observed alignment closely paralleled the preferred orientation of cortical cells recorded in the same electrode penetration.

A surprising feature of several penetrations was the apparent lack of overlap between cortical cell receptive fields and afferent arrays. There are a number of possible explanations for this observed lack of overlap. First, it is possible that the animal's eyes may have moved between the time of recording the cortical cell receptive fields and the time that pharmacological silencing of cortical activity had progressed sufficiently to record afferent receptive fields. Note that this period of drug infusion was often 


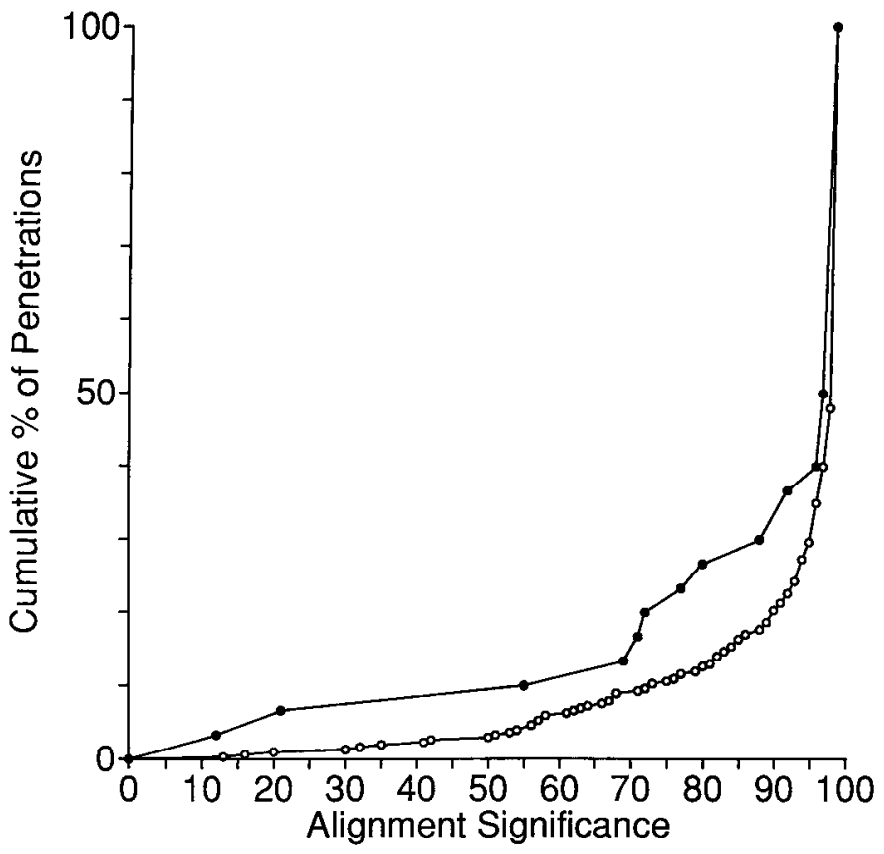

Figure 9. Alignment significance for experimental afferent arrays and for simulated arrays of afferents randomly chosen from an aggregate afferent-array universe. Random samples of afferents were drawn from the universe shown in Figure $8 \mathrm{~A}$, with the sizes of samples matched to the numbers of afferents recorded in the experimental arrays. Each experimental array was represented by 10 size-matched samples in the simulation. Alignment significance was calculated for each real array (normalized for cortical magnification as described in Figure 8 caption) and each simulated array. Cumulative percentages of penetrations are plotted at each alignment significance for the real data (solid symbols) and the simulated data (open symbols). The percentage rises faster for the real data, showing an overrepresentation of sites with low alignment significance in the real data as compared to the simulation. This suggests that two recorded sites where afferents were clustered are not due to sampling bias.

many hours long, much longer than the period of actual recording of afferent receptive fields (during which time the animals eyes could not have moved, because the same receptive fields were recorded at the same depth in layer IV at the beginning of the recordings as the electrode was advanced and then again at the end of the recordings as the electrode was retracted). Eye position during the experiment was monitored by plotting optic disk location, and no eye movements were observed. The possibility of eye movements could not completely be ruled out because of the considerable uncertainty in plotting the location of the optic disk in the small eye of the ferret. Second, the lack of overlap could be due to the normal scatter of receptive fields of cortical cells recorded in a single penetration through layer IV. It is possible that the plotted cortical cell receptive field might be at one edge of this scatter, while the afferents plotted might provide the input to a cell at the other edge. The cortical cells plotted, those at the top of layer IV, have receptive fields that are among the smallest found in area 17 and thus tend to have the largest scatter between receptive fields (Hubel and Wiesel, 1974). In the cat, cells in layers V and VI have receptive fields 2-10 times the size of cells in the upper layers (Gilbert, 1977). Therefore, afferents with receptive fields that do not overlap the receptive fields of the layer IV cell plotted may well provide inputs to neighboring cells in the same column. Finally, the nonoverlapping cortical and afferent receptive fields might result from the necessary compression of the whole eye map

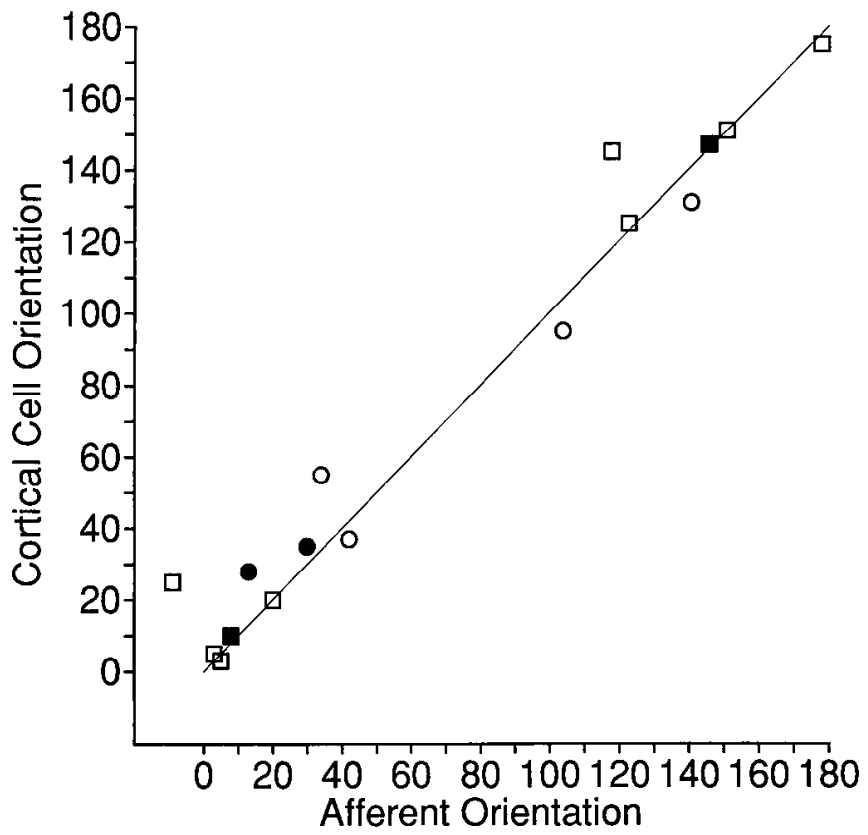

Figure 10. Correspondence between the cortical cell orientation preference and the angle of the principal axis of afferent receptive field arrays. Orientations are plotted following the normal mathematical conventions for angles: $0^{\circ}$ represents horizontal, with other orientations measured counterclockwise from horizontal. Open symbols represent oncenter afferents; solid symbols represent off-center afferents. Squares represent data collected under the blind protocol; circles represent data collected when the experimenter plotting afferent receptive fields knew the orientation preference of the cortical cells at that site. The diagonal line $(x=y)$ indicates the predicted result if cortical and afferent best orientations matched perfectly.

onto the segregated on- and off-center afferent patches seen in ferret cortex (Zahs and Stryker, 1988).

As discussed above, the methods used in this study cannot exclude the possibility that eye movements may have occurred between the times of cortical and afferent unit recordings. It is therefore possible that some of the mismatches seen in Figure 10 between the cortical cell preferred orientation and the angle of the principal axis of the afferent receptive field arrays could be due to uncontrolled torsional eye movements.

The fraction of the geniculocortical afferent inputs to an orientation column that was recorded in these experiments is not known. In the present study, we recorded between 8 and 30 afferent units per radial penetration through cortical layer IV. It is clear that not all the afferents present were studied, because additional afferents with electrical signals too small to be isolated were present at many recording sites (note the $20-\mu \mathrm{V}$ spikes in Fig. 2D). Comparisons between the numbers of geniculate cell receptive fields covering a region of visual space, the sizes of geniculocortical afferent arbors, and the magnifications of geniculate and cortical maps of the visual field have suggested that, in the cat, hundreds of geniculocortical afferent terminal arbors overlap a single vertical electrode penetration (Humphrey et al., 1985; Martin, 1988). Although these calculations have not been done for ferret area 17, the afferents we recorded presumably represent only a sample of those present. Nevertheless, there is no reason to assume that the sample encountered is not random with respect to receptive field position.

The observed match between the axis of elongation of the afferent receptive field array and the cortical cell orientation 
preference is consistent with Hubel and Wiesel's (1962) model of cortical simple cell orientation derived from geniculocortical input from LGN cells with receptive fields aligned in visual space. The present results cannot directly confirm this model, because they do not provide evidence about the geniculocortical afferents that converge onto a single cell. The afferent receptive field arrays recorded in this study indicate only that in most cases the aggregate geniculate input to a single orientation column is itself oriented, and that the orientation of geniculate input matches the orientation of cortical cells in the column.

A quantitative implementation of Hubel and Wiesel's (1962) model has shown that the orientation tuning seen in cortical cells could in principle be accounted for by geniculate inputs with aligned receptive fields (Ferster, 1987). An alternative model has shown that cortical cell orientation spccificity could bc produced by simple cells receiving input from two LGN cells of different center type with slightly offset receptive fields (Heggelund, 1986). This model would not predict any alignment of geniculate inputs to a cortical orientation column.

The arrangement of geniculocortical afferent inputs to single cortical cells has been studied by several techniques. Intracellular recordings from simple cells revealed that both excitatory and inhibitory postsynaptic potentials were greatest for elongated stimuli at the cells' preferred orientation (Ferster, 1986), but these recordings did not reveal which of the excitatory potentials were of geniculate origin.

Cross-correlation analysis of LGN and cortical neuron responses has revealed little evidence for elongated collections of geniculocortical inputs to single simple cells, but only a small number of inputs to a given cell could be found, and the most powerful of these inputs accounted for only an average of $11 \%$ of the cortical cell's discharge, suggesting that each cortical cell receives at least nine afferent inputs, and likely many more (Tanaka, 1983). Only if a comparable number of inputs had been found in the cross-correlation studies would it have been possible to determine whether the collection of inputs was significantly aligned.

The alignment of geniculocortical inputs may not be the sole basis of simple cell orientation. Other factors, including crossorientation inhibition, may also influence orientation selectivity. In two electrode penetrations in this study, cortical cell receptive fields were well oriented, but the afferent receptive field arrays were not elongated. Statistical analysis suggests that the lack of afferent receptive field alignment seen at these sites is real, not merely a result of sampling bias. It is possible that at such sites in cortex (Fig. $3 P, Q$ ) orientation selectivity is primarily due to inhibitory inputs from cortical neurons at orthogonal orientations. At other sites where afferents are well aligned (e.g., Fig. $3 A$ ), cortical cell orientation may result primarily from excitatory geniculocortical inputs aligned in visual space. Such a range of influence of excitatory and inhibitory factors on orientation selectivity has been seen previously in studies of cross-orientation inhibition (Pettigrew and Daniels, 1973; Sillito, 1975; Tsumoto et al., 1979; Sillito et al., 1980; Albus and Baumfalk, 1989; Eysel et al., 1989). When inhibitory inputs to oriented cells in cat visual cortex are abolished through application of GABA antagonists, results range from orientation selectivity somewhat reduced in $60 \%$ of simple cells (Albus and Baumfalk, 1989) to orientation selectivity abolished in $100 \%$ of simple cells (Sillito et al., 1980). Although some of the betweenand even within-study variability in those results may be due to differences in the degree of GABA antagonism produced, it may also reflect a real difference in the degree of remaining orientation selectivity produced by different degrees of alignment of geniculate inputs at different sites in cortex.

Cross-correlation analysis of corticocortical connections has not revealed selective inhibition from orthogonal orientations (Toyama et al., 1981; Hata et al., 1988), but has shown surprisingly strong common inputs to orientation columns selective for the same orientation and separated by as much as almost 3 $\mathrm{mm}$ (T'so et al., 1986). It is not clear whether cross-correlation techniques as applied have the sensitivity to detect relatively weak or diffuse inhibitory inputs (Moore et al., 1970), which may be powerful only in the aggregate (Hess et al., 1975).

Recent reports in the literature demonstrate that the use of particular kinds of visual stimuli can make LGN cells appear to be orientation selective (Vidyasagar and Urbas, 1982; Shou and Leventhal, 1989). This apparent geniculate orientation selectivity is unlikely to contribute to the orientation tuning of cortical neurons for two reasons: First, geniculate afferents show no orientation preference for stimuli such as the light bars used in this study. Figure $2 A$ is representative of the orientationtuning histograms of the geniculocortical afferents we recorded, and all recorded afferents responded to all orientations of light bars when tested by hand. Second, the apparent orientation selectivity of most LGN cells appears merely to reflect the fact that geniculate receptive fields are elliptical rather than perfectly circular. Thus, high-spatial-frequency stimuli beyond the resolving power of the longer axis of the receptive field are resolved when the stimulus is rotated to be perpendicular to the shorter axis (Shou and Leventhal, 1989).

The existence of oriented collections of geniculate inputs to orientation columns in the adult cortex does not reveal the mechanism by which orientation selectivity is established during development. Although it is possible that the oriented arrays of afferents are present very early in development and drive the formation of cortical orientation columns by providing the cortical cells with oriented input, it is also possible that geniculate input is not oriented early on, but rather that intracortical circuitry is responsible for first establishing orientation columns. Anatomical tracing techniques show that long intracortical connections, similar to those that connect columns of same orientation preference in adults (Gilbert and Wiesel, 1989), are present during the time that orientation columns are developing (Luhmann et al., 1986; Callaway and Katz, 1990). If such specific intracortical circuitry causes the formation of orientation columns, activity-dependent models such as those that have been used successfully to simulate the development of ocular dominance columns (e.g., Miller et al., 1989) would suggest that the geniculate inputs would then rearrange by a hebbian mechanism (Hebb, 1949) into the aligned arrangement found in the adult (Miller, 1990). Orientation-selective cortical cells are present at birth in the monkey (Hubel et al., 1977), develop without visual experience in the cat (Hubel and Wiesel, 1963b; Sherk and Stryker, 1976) and appear from our preliminary studies to be present before the time of natural eye opening in the ferret. Thus, if the early development of cortical orientation selectivity is activity dependent, it is likely to depend on spontaneous neuronal discharges rather than on visual stimulation.

\section{References}

Albus K, Baumfalk U (1989) Bicuculline induced changes in excitability and orientation selectivity of striate cortical neurones. Soc Neurosci Abstr 15:324. 
Blakemore C, Tobin EA (1972) Lateral inhibition between orientation detectors in the cat's visual cortex. Exp Brain Res 15:439-440.

Callaway EM, Katz LC (1990) Emergence and refinement of clustered horizontal connections in cat striate cortex. J Neurosci 10:1134-1153.

Creutzfeldt OD, Kuhnt U, Benevento LA (1974) An intracellular analysis of visual cortical neurones response to moving stimuli: response in cooperative neural network. Exp Brain Res 21:251-274.

Eysel UT, Crook JM, Machemer HF (1989) Orientation tuning in cat striate cortex involves intracortical suppression of cross-orientation excitation. Soc Neurosci Abstr 15:324.

Ferster D (1986) Orientation selectivity of synaptic potentials in neurons of cat primary visual cortex. J Neurosci 6:1284-1301.

Ferster D (1987) Origin of orientation-selective EPSPs in simple cells of cat visual cortex. J Neurosci 7:1780-1791.

Gilbert CD (1977) Laminar differences in receptive field properties of cells in cat primary visual cortex. J Physiol (Lond) 268:391-421.

Gilbert CD, Wiesel TN (1989) Columnar specificity of intrinsic connections in cat visual cortex. J Neurosci 9:2432-2442.

Hata Y, Tsumoto T, Sato H, Hagihara K, Tamura H (1988) Inhibition contributes to orientation selectivity in visual cortex of cat. Nature 335:815-817.

Hebb DO (1949) The organization of behaviour. New York: Wiley.

Heggelund P (1986) Quantitative studies of the discharge fields of single cells in cat striate cortex. J Physiol (Lond) 373:277-292.

Hess R, Negishi K, Creutzfeldt O (1975) The horizontal spread of intracortical inhibition in the visual cortex. Exp Brain Res 22:415419.

Hubel DH (1957) Tungsten microelectrode for recording from single units. Science 125:549-550.

Hubel DH, Wiesel TN (1962) Receptive fields, binocular interaction and functional architecture in the cat's visual cortex. J Physiol (Lond) 160:106-154.

Hubel DH, Wiesel TN (1963a) Shape and arrangement of columns in cat's striate cortex. J Physiol (Lond) 165:559-568.

Hubel DH, Wiesel TN (1963b) Receptive fields of cells in striate cortex of very young, visually inexperienced kittens. J Neurophysiol 26:994 1002.

Hubel DH, Wiesel TN (1974) Uniformity of monkey striate cortex: a parallel relationship between field size, scatter, and magnification factor. J Comp Neurol 158:295-305.

Hubel DH, Wiesel TN, LeVay S (1977) Plasticity of ocular dominance columns in monkey striate cortex. Philos Trans R Soc Lond [Biol] 278:377-409.

Humphrey AL, Sur M, Uhlrich DJ, Sherman SM (1985) Projection patterns of individual $X$ - and $Y$-cell axons from the lateral geniculate nucleus to cortical area 17 in the cat. J Comp Neurol 233:159-189.

Luhmann HJ, Martinez Millan L, Singer W (1986) Development of horizontal intrinsic connections in cat striate cortex. Exp Brain Res $63: 443-448$.
Martin KAC (1988) The Wellcome prize lecture: from single cells to simple circuits in the cerebral cortex. Q J Exp Physiol 73:637-702.

Miller KD (1990) Cortical organization of orientation selectivity emerges from interactions between on- and off-center inputs. Soc Neurosci Abstr 16:798.

Miller KD, Keller JB, Stryker MP (1989) Ocular dominance column development: analysis and simulation. Science 245:605-615.

Moore GP, Perkel DH, Segundo JP (1970) Statistical signs of synaptic interaction in neurons. Biophys J 10:876-900.

Pettigrew JD, Daniels JD (1973) GABA antagonism in visual cortex: different effects on simple, complex, and hypercomplex neurons. Science 182:81-83.

Redies C, Diksic M, Riml H (1990) Functional organization in the ferret visual cortex: a double-label 2-deoxyglucose study. J Neurosci 10:2791-2803.

Schoppmann A, Stryker MP (1981) Physiological evidence that the 2-deoxyglucose method reveals orientation columns in cat visual cortex. Nature 293:574-576.

Sherk H, Stryker MP (1976) Quantitative study of cortical orientation selectivity in visually inexperienced kitten. J Neurophysiol 39:63-70.

Shou T, Leventhal AG (1989) Organized arrangement of orientationsensitive relay cells in the cat's dorsal lateral geniculate nucleus. J Neurosci 9:4287-4302.

Sillito AM (1975) The contribution of inhibitory mechanisms to the receptive field properties of neurones in the striate cortex of the cat. J Physiol (Lond) 250:305-329.

Sillito AM, Kemp JA, Milson JA, Berardi N (1980) A re-evaluation of the mechanisms underlying simple cell orientation selectivity. Brain Res 194:517-520.

Singer W (1981) Topographic organization of orientation columns in the cat visual cortex. Exp Brain Res 44:431-436.

Tanaka K (1983) Cross-correlation analysis of geniculostriate neuronal relationships in cats. J Neurophysiol 49:1303-1318.

Toyama K, Kimura M, Tanaka K (1981) Cross-correlation analysis of interneural activity in cat visual cortex. J Neurophysiol 46:191201.

T'so DY, Gilbert CD, Wiesel TN (1986) Relationships between horizontal interactions and functional architecture as revealed by crosscorrelation analysis. J Neurosci 6:1160-1170.

Tsumoto T, Eckart W, Creutzfeldt OD (1979) Modification of orientation sensitivity of cat visual cortex neurones by removal of GABA mediated inhibition. Exp Brain Res 34:351-363.

Vidyasagar TR, Urbas JV (1982) Orientation sensitivity of cat LGN neurones with and without inputs from visual cortical areas 17 and 18. Exp Brain Res 46:157-169.

Zahs KR, Stryker MP (1988) Segregation of on and off afferents to ferret visual cortex. J Neurophysiol 59:1410-1429. 